\title{
Performance Evaluation of Hot Mix Asphalt Concrete by Using Polymeric Waste Polyethylene
}

\author{
Hakeem Jan ${ }^{\mathrm{a}}$, Mohamad Yusri Aman ${ }^{\mathrm{b}}$, M.Tawab ${ }^{\mathrm{c}}$, and K.Ali ${ }^{\mathrm{c}}$ \\ a.Ph.D Scholar Faculty of Civil and Environmental Engineering, Universiti Tun Hussein Onn \\ Malaysia, 86400 Batu Pahat, Johor, Malaysia. \\ b.Associate Prof. Faculty of Civil and Environmental Engineering, Universiti Tun Hussein Onn \\ Malaysia, 86400 Batu Pahat, Johor, Malaysia. \\ c.Lab Engineer Faculty of Civil Engineering SUIT Peshawar.
}

khyberpass08@gmail.com, mdyusri@uthm.edu.my and tawab4@gmail.com

\begin{abstract}
Asphalt plays an important role in the construction of flexible pavements due to its binding properties. However, it has poor properties that are improved using synthetic polymers. This study evaluated performance of hot asphalt concrete by use of polymeric waste polyethylene based on standard methods, including AASHTO and Marshall Stability. The results revealed a decrease in penetration value with increasing polymer content in Asphalt, suggesting that the polymer hardens the modified asphalt; increasing softening point with increasing polyethylene content due to the polyethylene added; and increasing fire and flash points of the modified asphalt with increasing polythene content, suggesting low propensity of hazardous situation since the inflammability of asphalt decreases with increasing polymer content. The study concluded that waste plastic materials are effective in modifying asphalt for construction of flexible pavements despite the need to ascertain the exact proportions of the mix for achieving the best modified bituminous concrete.
\end{abstract}

Keywords: Asphalt, modified asphalt mix, flexible pavements.

\section{Introduction}

Asphalt is a mineral aggregate with dark brown to black colour, which can be obtained naturally from lakes or artificially from petroleum processing. With increasing road traffic and insufficient maintenance as a result of funding financial constraints, the roads are rapidly deteriorating. This situation has prompted the use of other alternatives, including better quality materials, cost-effective construction methods and allocation of adequate funds for road maintenance, improvement and innovative design. Research has cited various factors that affect flexible course performance like the component properties (binder, aggregate as well as additive) and their proportion in the mix [1]. It is well established that polymers may be used as one of the additives in asphalt to produce modified Asphalt [1,2].

Hakeem, Yusri, Muhammad and Kashif. 
Moreover, polymers increase the asphalt stiffness as well as ensuring improved temperature susceptibility. According to Awwad and Shbeeb [2] and Coplantz, Yapp and Finn [3], higher stiffness ensures improved modified Asphalt rutting resistance during hot climates besides using relatively asphalt with softer base so as to achieve better performance in low temperature. It is also suggested that polymer modified binders possess better adhesive together with cohesive properties $[3,4,5,6]$. Polymers may also serve as additives of asphalt concrete mixtures for processing aggregate coating material. Such coatings improve the aggregate surface toughness and thereby ensuring superior engineering properties in production of asphalt mixtures $[6,7]$. There is increasing use of asphalt in construction of road pavement to bind aggregates [10]. Nonetheless, the asphalt mixture/coating layer is susceptible to severe temperature like high temperature rutting to medium temperature fatigue as well as cracking damages due to low temperature. This explains the use of asphalt mixture modification to ensure improved application. Improved asphalt properties may be achieved through use of suitable starting crude oil and ensuring controlled refinery processes, both of which are very difficult to realize [11]. According to these authors, air blowing hardens asphalt while fluxing agents/ diluent oils may be used to soften it. Moreover, polymer addition ensures significant asphalt quality improvement. This is why asphalt modification with polymers remains the common method for quality improvement, particularly for rheological properties [12].

Apparently, pavements defects like rutting during high temperatures, cracking in regions with low temperature and others arise due to traffic loads and the inadequate ability of asphalt concrete to resist temperature changes. Moreover, increased traffic factors like heavier loads and higher traffic volume as well as higher tire pressure require road pavements with higher performance, which in turn requires less susceptible asphalt to factors such as high temperature rutting and low temperature cracking, and must possess excellent bonding with stone aggregates. This study evaluated performance of hot asphalt concrete by use of polymeric waste polyethylene.

With the depletable nature of asphalt binders and the environmental and social hazards of waste plastic, this paper seeks to determine the effectiveness of using polymeric waste polyethylene to modify asphalt mixes and to optimize the penetration values, softening points, fire points and flash points to make the asphalt mixes more durable and high temperature-resistant.

\section{Materials and Methods}

This experiment used Polyethylene to modify asphalt mixtures. Black stone were collected and crushed into coarse aggregate for performance evaluation of polyethylene on hot asphalt mixtures. The finer dust $(<0.075 \mathrm{~mm})$ was obtained from the aggregate blend of Domar sand and used as filler material. During crushing of the stone, a lot of dust was produced while some stone dust was trapped in crushed stone. To ensure optimum use of stone dust, the dust was mixed with fine sand.

2.1 Polyethylene: This experiment used low density white polyethylene bags from local market as well as domestic wastes. The polyethylene was well cleaned and then shredded into particles of 2-3 mm for recycled polyethylene preparation. To meet the recommended requirements by Rahman, Sobhan and Ahmed [13], the polythene used had specific gravity of 0.94 and melting temperature of $115^{\circ} \mathrm{C}$.

2.2 Bituminous Materials and Preparation: Samples of $80 / 100$ penetration grade binding asphalt were tested in accordance with AASHTO to evaluate various properties of asphalt, 
namely Flash \& fire points, Penetration value as well as Softening points. Notably, the asphalt binder properties were kept within the penetrating specification of asphalt grade 80/100.

Asphalt specimens were prepared for evaluating the Marshall stability associated with mixture of asphalt and polyethylene. This was done using test procedure by Bruce Marshall that was advanced by the U.S engineer corps. Aggregates of about $1200 \mathrm{~g}$ were therefore used to prepare there specimen with diameter of $101.6 \mathrm{~mm}$ and thickness of about $63.5 \mathrm{~mm}$ of pure asphalt. In addition, the optimum asphalt content for preparing the mixture was determined by the same method. Notably, the Marshall Stability as well as flow test were used to predict the performance measure of stability of the mixture, load carrying capacity as well as the permanent deformation resistance. Overall, 9 test samples were used to determine the content of optimum asphalt binder with varying asphalt proportions.

2.3 Aggregates: Black stone was crushed into a coarse aggregate, and further broken manually into $25.00 \mathrm{~mm}$ downgrade pieces. As stated by The Asphalt Institute [14], all the coarse aggregate had to remain on $2.36 \mathrm{~mm}$ sieve. A fine aggregate that passed through $2.36 \mathrm{~mm}$ but retained by $0.075 \mathrm{~mm}$ sieve was obtained from aggregate blend/ coarse sand. To meet the requirements of mineral filler recommended by Rahman, Sobhan and Ahmed [13], a non-plastic sand sieve with less than $0.075 \mathrm{~mm}$ was used, while the apparent filler specific gravity was 2.63.

2.4 Gradation of Aggregates: Evaluation of the asphalt concrete mix that is modified with additives in terms of behavior requires a continuously graded bituminous macadam aggregate. However the later requires uniform aggregate blend gradation so as to achieve a dense mix with air-free controlled optimum content for construction of stable as well as durable flexible pavement $[15$

\section{Results}

This study evaluated the performance of hot asphalt concrete based on fire, flash and softening points as well as the penetration of asphalt. To achieve this, samples of varying grinded plastic (polymer) with asphalt. The results obtained are presented in detail in the following sections.

3.1 Penetration Value: The results on comparison of the polymer added and penetration value showed an inverse variation with $0 \%$ of polymer added at highest penetration value of 85 and $16 \%$ polymer added at penetration value of 0 . The penetration value decreased gradually with an increase in the percentage added in asphalt up to a penetration value of 0 with a polymer percentage of $16 \%$ (Table and Figure 1). The mean penetration value $44.111 \pm \mathrm{SD}=27.980$ and Std. Error $=9.327$. 
Table 1. Comparison between Polymers added (\%) and Penetration value

\begin{tabular}{cc}
\hline Polymer added in Asphalt (\%) & Penetration Value \\
\hline 0 & 85 \\
2 & 70 \\
4 & 64 \\
6 & 57 \\
8 & 46 \\
10 & 38 \\
12 & 24 \\
14 & 13 \\
16 & 0 \\
\hline
\end{tabular}

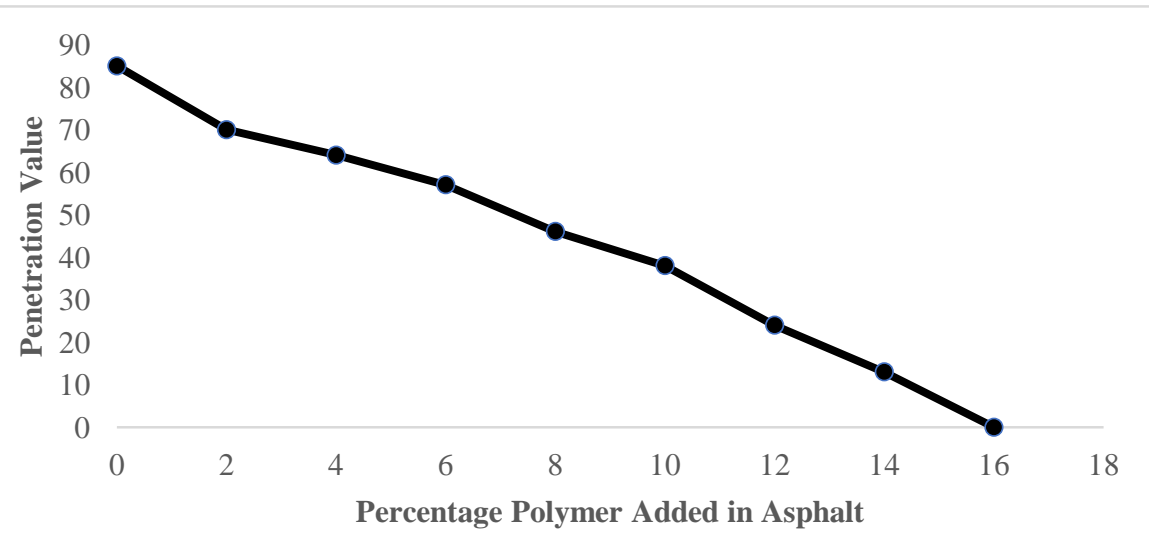

Fig. 1. Comparison between Polymers added (\%) and Penetration Value

3.2 Softening Points: The percentage polymer in asphalt was found to be directly proportional to the softening point of the asphalt. Asphalt with $0 \%$ polymer had a softening point of $55 \mathrm{C}^{\circ}$, whereas asphalt with $4 \%$ polymer had a softening point of $68 \mathrm{C}^{\circ}$ (Table and Figure 2). The mean softening point was $\pm \mathrm{SD}=27.980$ and Std. Error $=9.327$.

Table 2. Comparison between Polymers added (\%) and Softening Point.
Polymer added in Asphalt (\%)
Softening Point $\left(\mathrm{C}^{\circ}\right)$

0

1 


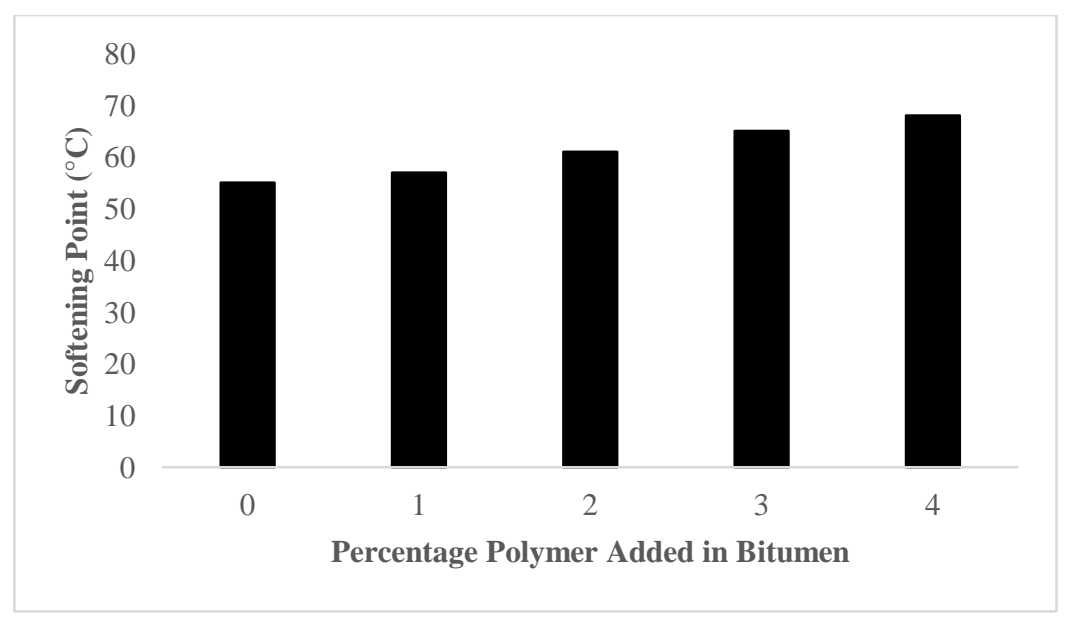

Fig. 2. Comparison between Polymers added (\%) and Penetration Value

\subsection{Percentage of Polymer added, Fire point and Flash Point:}

When percentage of polymer added, fire point and flash point are compared, the results showed that the percentage polymer added in asphalt was directly proportional to both the fire point and the flash point. Pure asphalt had fire and flash points of $238 \mathrm{C}^{\circ}$ and $246 \mathrm{C}^{\circ}$ respectively. At 1 $\%$ polymer added, the fire and flash points were $241 \mathrm{C}^{\circ}$ and $252 \mathrm{C}^{\circ}$; while at $4 \%$ polymer added, the fire and flash points were $268 \mathrm{C}^{\circ}$ and $274 \mathrm{C}^{\circ}$ respectively. The mean fire point was $250.8 \pm \mathrm{SD}=12.194$ and Std. Error $=5.453$. On the other hand, the mean flash point was 260.8 $\pm \mathrm{SD}=11.649$ and Std. Error $=5.210$ (Table and Figure 3).

Table 3. Percentage of Polymer added, Fire point and Flash Point.
Polymer (\%) added in Asphalt
Fire point $\left(\mathrm{C}^{\circ}\right)$
Flash Point $\left(\mathrm{C}^{\circ}\right)$

0

238

1

241

2

250

263

3

257

269

4

268

274 


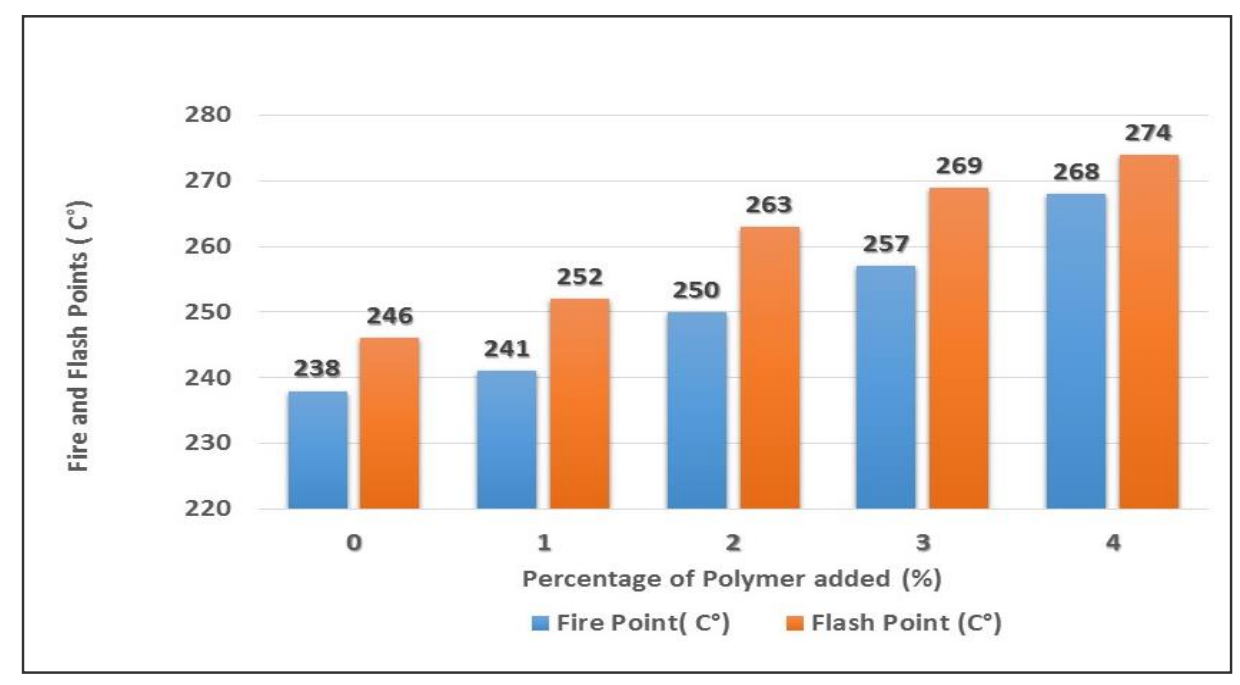

Fig. 3. Comparison between Polymers added (\%) and Penetration Value

\section{Discussion}

Asphalt is used to construct flexible pavements by binding the aggregate together through coating the aggregates. In addition, the material promotes the strength as well as the life of the road pavement. However, due to its poor properties like resistance towards water, it is commonly improved by modifying its rheological properties by mixing with synthetic polymers such as rubber and plastics. Since the use of waste plastic with asphalt is similar to using polymer modified asphalt, this experiment used waste plastic to evaluated performance of hot asphalt concrete based on fire, flash and softening points as well as penetration of Asphalt.

This study found a decrease in penetration value with increasing polymer content in asphalt, suggesting harder modifying binder. The penetration value of asphalt is a measure of the consistency of the asphalt. The consistency of the asphalt enables the engineer to determine the degree of resistance that the asphalt will have to continuous deformation under stress. From the experiment, the inverse relationship between the percentage polymer added in asphalt and the penetration value indicates that with an increased percentage of polymer in the asphalt, the amount of permissible stresses on the asphalt reduces significantly. These findings support the findings by Justo and Veeraraghavan [16] that the values of penetration and ductility of modified asphalt reduce with increasing plastic content up to a weight of $12 \%$. In another study by Sabina, Khan, Sharma D K and Sharma B M [17], performance evaluation of bituminous mixes with plastic (8\%) and asphalt (15\%) was compared to mixture of conventional bituminous concrete (i.e. penetration grade asphalt with 60/70). The findings showed improved properties such as Marshall and retained stability to indirect tensile strength as well as rutting with polymeric modified bituminous concrete. As stated by Imtiyaz [18], the modified mixes are resistant to permanent deformation in elevated temperatures.

The results showed an increase in the softening point value with increasing polyethylene content. This is explained by the higher soften temperature associated with polyethylene. Of note, higher softening points are preferred in warm climates since they are associated with lower temperature susceptibility. These findings are in agreement with a previous study by Justo and 
Veeraraghavan (2002) that the softening point of asphalt mix increases with an increase in the plastic content up to a weight of $8.0 \%$. Waste plastics are thermoplastic polymers and they are non-biodegradable. These thermoplastic polymers have no significant use when disposed at dumping sites rather than being recycled into different plastic products, which are still pollutants to the environment. As stated by Vasudevan and Rajasekan [19], these polymeric materials improve the binding properties of asphalt than conventional asphalt for pavement construction. Moreover, the use of blended asphalt with waste plastic improves the properties of blended asphalt and addresses challenges associated with plastic waste disposal common with many nations and thereby improves the sanitation systems and employment creation for the collectors.

Moreover, the blend increases the softening point but reduces the penetration value with eventual suitable ductility. This view is supported by Punith [20], who reported the likelihood of improving the performance of modified bituminous road pavements. This is attributable to the lack of gas evolution between $130-180^{\circ} \mathrm{C}$, yet waste plastics softens on heating at around $130^{\circ} \mathrm{C}$ in order to confer the binding property to asphalt. This explains why it is used for binding purposes in road construction. This study found an increase in fire and flash points of the modified asphalt increased with increasing polythene content. This suggests low propensity of hazardous situation since the inflammability of asphalt decreases with increasing polymer content. Put in other words, the blended asphalt has improved resistance to burning; implying that the road with polymer asphalt blended surfaces is less likely to be affected by fire hazards. Studies have shown that polymer modified asphalt is highly resistant to temperature and water, explaining why it is used for construction of flexible road pavements [21].

According to Afroz et al [22], polymer modified asphalt exhibits better rheological properties essential for construction of highways. For instance, asphalt ensures flexible pavement construction by binding the aggregates together through coating the surface of aggregates. This coating results in improved strength as well as life of the road pavements. However, asphalt has poor water resistance compared with polymeric modified asphalt which has better temperature and water resistance. Zoorob and Suparma [23] reported that recycled plastics predominantly comprise of low density. Polyethylene (LDPE) plus polypropylene (PP) when used for conventional bituminous concrete mixtures to improve durability together with fatigue life. In their research, Apurva and Chavan, [24] found that blended polymer-asphalt helps to promote better asphalt binding of plastic coated aggregate as a result of increased bonding and surface contact area between polymeric materials and asphalt. Moreover, the polymer coatings reduce voids, and therefore prevent absorption of moisture and asphalt oxidation by entrapped air that collectively cause reduced rutting, raveling and pothole formation.

In another study by Sreedevi and Salini [25] to explore pavement performance of roads surfaced with bituminous mixtures and coated aggregates, it was concluded that using waste polymeric materials for road construction may prevent environmental pollution, increase the road service life, reduce petroleum product consumption and generate income to the society through job creation. Evidently, blended asphalt with waste plastics has improved rheological properties. However, the evaluation of the binder performance relies heavily on the proportion of polymeric material blended asphalt. Other benefits associated with the use polymeric materials in pavement construction are reduction of waste plastics in the environment with eventual significant reduction in environment pollution and improved hygiene and sanitation systems, and creation of employment for garbage collectors. 


\section{Conclusion}

This study found that waste plastic materials may be effectively used to modify asphalt for construction of flexible pavements. This may be achieved by mixing processed waste plastic of varying proportions by weight of asphalt to ensure substantial improvement in the Marshall stability, strength, and other related properties of the modified bituminous concrete in order to achieve longevity and better performance of pavement with minimal asphalt usage. The process is friendly to the environment. However, the study recommends further studies to ascertain the exact proportions of the mix that achieve the best modified bituminous concrete.

\section{Acknowledgment}

The authors of this study acknowledge the center of graduate studies (CGS) UTHM Malaysia that contributed to the success of this research work to support the technical and financial.

\section{References}

[1] Subagio, B.S, Kosasih, D. Busnial, and Tenrilangi, D. (2005). Development of stiffness modulus and plastic deformation characteristics of porous asphalt mixture using tafpack super. Proceed. Eastern Asia Soc. Transportation Studies, 5, $803-812$.

[2] Awwad, M. T. and Shbeeb, L. (2007). The use of polyethylene in hot asphalt mixtures. American Journal of Applied Sciences, 4 (6), 390-396.

[3] Coplantz, J.S., Yapp, M. T., and Finn, F. N (1993). Review of relationships between modified asphalt properties and pavement performance. SHRP-A-631, Strategic Highway Res. Program, National Res. Council Washington, USA.

[4] Newman, K. (2004). Polymer-modified asphalt mixtures for heavy-duty pavements: fatigue characteristics as measured by flexural beam testing. FAA Worldwide Airport Technol. Transfer Conf. Atlantic City, New Jersey, USA.

[5] Hansen, K. R., Robert, B. M., Brian, P., and Stonex, A. (n.d). Current and future use of nonbituminous components of bituminous paving mixtures. Committee on Characteristics of Non bituminous Components of Bituminous Paving Mixtures: A2D02. Onlinepubs.trb.org/ online pubs /millennium /00079.pdf.

[6] Robin, L. Schroeder (1994).The use of recycled materials in highway construction. Journal, Public Roads, 58, 2.

[7] Amit, G., Zamre, G. S., Renge, V. C., Bharsakalea, G. R., and Tayde, S (2012). Utilization of waste plastic in asphalting of roads. Sci. Revs. Chem. Commun., 2(2), 147-157.

[8] Gawande, A., Zamare, G., Renge, V. C., Tayde, S. \& Bharsakale, G. (2012). An overview on waste plastic utilization in Asphalting of roads. Engineering Research and Studies Journal, 3(2), 1-5.

[9] Jabarin, A. S. (1996). Polyethylene terephthalate chemistry and preparation. The Polymeric Materials Encyclopedia, CRC Press Inc.

[10] Akmal, N. \& Usmani, A. M. (1999). Application of asphalt-containing materials. Polym News, 24,136-40.

[11] Yuonne, B. \& Yajaira, M. P. M. R (2001). Polymer modified asphalt. Vision Technologica, 9 (1), 39-48.

[12] Uranga, O. G (2008). Rheological property of asphalt modified with polyethylene and polyethylene based blends. 
[13] Rahman, M.N., Sobhan, M.A., \& Ahmed, T.U. (2012). Effects of waste polyethylene on bituminous mixes. Proceedings of the 1st International Conference on Civil Engineering for Sustainable Development, Khulna, Bangladesh

[14] The Asphalt Institute (1984). Mix Design Methods for Asphalt Concrete and Other Hot-Mix Types. 6th Edition, Asphalt Institute, Lexington, KY, USA.

[15] Sobhan, MA, Mofiz, SA and Rasel, HM (2011). Effect of gradation and compactive effort on the properties of bituminous mixes with waste concrete aggregates. International Journal of Civil and Environmental Engineering, 11(4), 18-21

[16] Justo, C.E.G. \& Veeraragavan, A. (2002). Utilization of Waste Plastic Bags in Bituminous Mix for Improved Performance of Roads. Centre for Transportation Engineering, Bangalore University, Bangalore, India.

[17] Sabina, Tabrez, A. Khan, Sangita, Sharma, D. K. \& Sharma, B. M. (2009). Performance Evaluation Of Waste Plastic/Polymer Modified Bituminous Concrete Mixes. Journal of scientific and industrial research, 68, 975-979

[18] Mohd, Imtiyaz (2002). Adhesion Characteristics Study on Waste Plastics Modified Asphalt. International journal of technology research in engineering, 2(9), 2077-2080

[19] Dr.Vasudevan, R. \& Rajasekaran, S. (2007). Utilization of Waste Plastics in Construction of Flexible Pavements (Reuse of waste plastics - a path - breaking initiative).

[20] Punith, V.S (2001). Study of the Effect of Plastic Modifier on Bituminous Mix Properties. Mohd. Imtiyaz (2002). Adhesion Characteristics Study on Waste Plastics Modified Asphalt.

[21] Dr. Gupta, Y. P, Shailendra, Tiwari \& Pandey, J. K. (2010, March). Utilisation of Plastic Waste in Construction of Bituminous Roads. NBM \& CW, p. 92.

[22] Afroz, Sultana, S.K. \& Prasad, K.S.B. (2012). Utilization of waste plastic as a strength modifier in surface course of flexible and rigid pavements. International journal of engineering research and applications, 2(4), 1185-1191.

[23] Zoorob, S.E. \& Suparma L.B. (2000). Laboratory design and investigation of the properties of continuously graded asphalt concrete containing recycled plastics aggregates replacement (Plastiphalt). Cement concrete composites, 22:233-42

[24] Apurva, Chavan, J. (2013). Use of plastic waste in flexible pavements. International journal of application or innovation in engineering and management, 2(4), 540-552.

[25] Sreedevi, B.G. \& Salini, P.N. (2013). Pavement performance on roads surfaced using bituminous mixtures with coated aggregates. International journal of Engineering research \& technology, 2(9), 14915 